\title{
COMUNICANDO UN DESASTRE. UN \\ MAPA, DIVERSOS MENSAJEROS Y \\ LAS NOTICIAS IMPERIALES DE UNA
}

\section{SUBLEVACIÓN IN DÍGENA (ARAUC0, 1598-1610)}

José Araneda Riquelme $e^{(a)}$

COMMUNICATING A DISASTER. A MAP, VARIOUS MESSENGERS, AND THE IMPERIAL NEWS ABOUT AN INDIGENOUS UPRISING (ARAUCO, 1598-1610)

COMUNICANDO UM DESASTRE. UM MAPA, DIVERSOS MENSAGEIROS E AS NOTÍCIAS IMPERIAIS DE UMA REVOLTA INDÍGENA (ARAUCO, 1598-1610)

Fecha de recepción: 17 de noviembre del 2020

Fecha de aprobación: 12 de diciembre del 2020

Disponible en línea: 1 de enero del 2021

Sugerencia de citación:

Araneda Riquelme, J. (2021). Comunicando un desastre. Un mapa, diversos mensajeros y las noticias imperiales de una sublevación indígena (Arauco, 1598-1610). Razón Crítica, 10, 121-146, https://doi. org/10.21789/25007807.1713

(a) José Araneda Riquelme Candidato a Doctor

Dottorato in Letteratura, Arte e Storia dell'Europa medioevale e moderna

Scuola Normale Superiore, Italia

https://orcid.org/0000-0002-5785-3472

jose.aranedariquelme@sns.it 


\section{R E S U M E N}

En este trabajo se analiza cómo se comunicó el llamado "Desastre" de Curalaba y la muerte del gobernador Martín Oñez de Loyola, en manos indígenas en 1598. A través de un mapa de 1610, que buscó representar el desastre y la consecuente sublevación indígena, se intenta dar cuenta de los problemas de comunicación e información del Chile a inicios de siglo. Mediante diversos agentes, con informaciones cruzadas entre Lima, Santiago de Chile y Madrid, se fue construyendo tanto una imagen del infortunio como una forma de diagnóstico de la situación y proyectar la reversibilidad del fracaso militar. Así, los mensajeros y procuradores comunicaron y representaron la desgracia de Chile en la corte, donde el Virrey tuvo una voz protagonista.

PALABRAS CLAVE: comunicación; Chile; desastre; Imperio Español; mapa; procuradores. 


\section{A B S T R A C T}

This work studies how the so-called "Disaster" of Curalaba and the death of Governor Martín Oñez de Loyola, at the hands of indigenous people, in 1598, were communicated. By using a map dated back to 1610 , which sought to represent the disaster and the resulting indigenous uprising, an attempt is made to account for the communication and information problems lived in Chile at the beginning of the XVII century. Through various agents, and information exchanged between Lima, Santiago de Chile and Madrid, we built an image of this misfortunate event as a way of diagnosing the situation and depicting the reversibility of military failure. Thus, both messengers and procurators communicated and represented the disgrace of Chile at court, where the Viceroy of the time had a leading voice.

KEYWORDS: Communication; Chile; disaster; Spanish Empire; map; procurators.

\section{R E S U M O}

Neste trabalho, é analisado como foram comunicados o chamado “desastre" de Curalaba e a morte do governador Martín Oñez de Loyola, em mãos indígenas em 1598. Por meio de um mapa de 1610, que pretendeu representar o desastre e a consequente revolta indígena, tentase evidenciar os problemas de comunicação e informação do Chile no início do século. Mediante diversos agentes, com informações cruzadas entre Lima, Santiago do Chile e Madri, foram sendo construídos tanto uma imagem do infortúnio quanto uma forma de diagnóstico da situação, e projetar a reversibilidade do fracasso militar. Assim, os mensageiros e os procuradores comunicaram e representaram a desgraça do Chile na corte, onde o vice-rei teve uma voz protagonista.

PALAVRAS-CHAVE: comunicação; Chile; desastre; Império espanhol; mapa; procuradores. 


\section{N T R O D U C C I Ó N}

El llamado "Desastre" de Curalaba, victoria indígena sobre el ejército español del gobernador Martín García Oñez de Loyola en 1598, ha sido históricamente tratado como un hito fundamental en la construcción del Chile Colonial. Como acontecimiento, instaló una frontera física y cultural entre los territorios españoles y aquellos reche-mapuche en el río Biobío. Pero poco se ha debatido sobre el problema de la comunicación de este suceso, cómo la noticia circuló desde este territorio indómito hasta los centros de poder virreinal e imperial. El objetivo de este artículo, por tanto, es comprender cómo se comunicó el desastre que llevó a la destrucción de las siete ciudades hacia 1604.

Figura 1. Parte del mapa de la gobernación de Chile y la destrucción de las ciudades (1610)

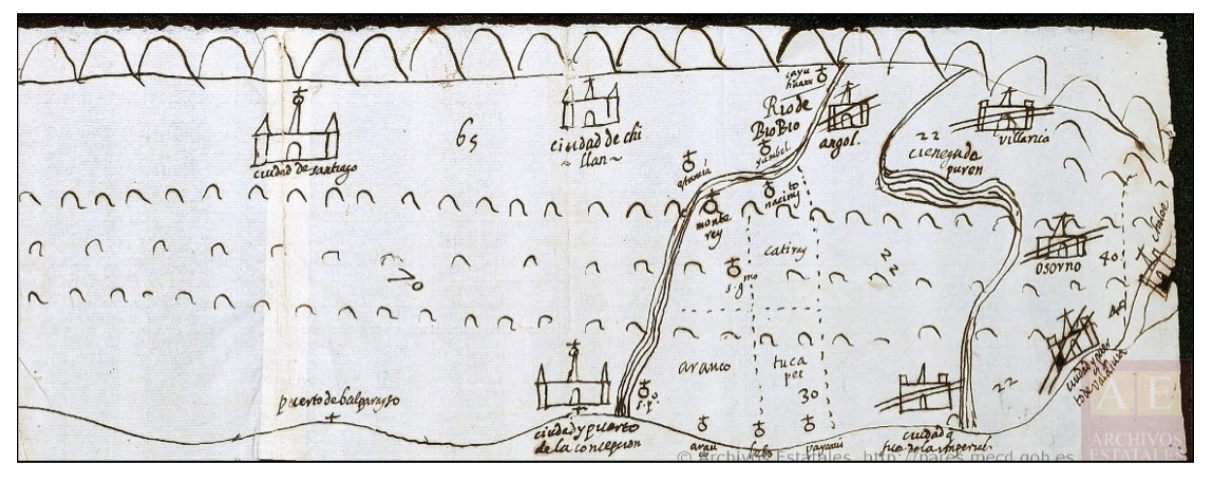

Fuente: Archivo General de Indias, MP-PERU_CHILE,172. Originalmente en AGI, Patronato, 229. 
Por ello, es interesante analizar el mapa de la figura 1. Cercano al año de 1610, se encontraba inicialmente en la sección "Patronato" del Archivo General de Indias, correspondiente al volumen 229, sobre la "Guerra, socorro y pacificación del Reino de Chile, 1607-1622". No sabemos su autoría ni donde fue realizado, sin embargo, da cuenta de un conocimiento geográfico empírico de las condiciones fronterizas del Chile posterior a la sublevación mapuche ${ }^{1}$. En él, se ilustra lo que generó este "desastre", la destrucción de las siete ciudades españolas (15981604), siendo tachadas en la representación cartográfica ${ }^{2}$. Representa un momento donde la destrucción se detiene después de un proceso largo casi 6 años - de continuas batallas y enfrentamientos.

Desde un análisis etimológico, un "desastre", como ha identificado Pablo Castro García (2020), puede ser vinculado, por un lado, a la idea de fortuna, destino y azar en una dimensión funesta; y, por otro, con una acepción asociada al "oscurecimiento" o "el no ver". En ese sentido, la experiencia del desastre observado en el mapa representa un golpe desdichado de la fortuna, a partir de la inesperada muerte del gobernador, pero a la vez, un oscurecimiento generado por la desorientación de la misma situación. Este evento, el Desastre de Curalaba, generó una serie de noticias que culminaron con la construcción de este mapa. En ese sentido, la historia de los distintos mensajeros, muchos que ayudaron a la comprensión del mapa, participaron en la comunicación del "infortunio", iluminándolo desde su inicio, como se relata el poema épico Purén Indómito:

Cuando Apolo dejó nuestro hemisferio

Y se entró por las puertas del ocaso,

Entró dentro de Ongol [Angol] el mensajero,

Y en él la nueva dio del triste caso:

Mirad si el yanacona fue lijero,

Y si alargar el medio le hizo el paso;

Mas siempre a aquel que lleva nuevas malas

El tiempo suele darle prestas alas.

(Arias de Saavedra \& Álvarez de Toledo, 1862).

1 Este mapa también ha sido analizado por Ricardo Padrón (2004, p. 81).

2 A pesar de que, en realidad, no eran más que fuertes que no podían ser comparables a las pequeñas villas en Santiago y Concepción. 
Palabras como "ocaso", "triste” y "nuevas malas" representan el desastre en este relato a inicios del siglo xvi. Todo sucedió repentinamente en la noche del 23 de diciembre de 1598, el gobernador de Chile, Martín García Óñez de Loyola, junto con su tropa dormía en el paraje de Curalaba, emplazado entre dos de las principales ciudades del disputado territorio al sur del río Biobío: la ciudad de los Confines de Angol y la ciudad de La Imperial. Se estaban desplazando por el territorio rechemapuche $^{3}$ en el contexto de la resistencia indígena contra el dominio español, lo que se ha llamado la Guerra de Arauco. Sin embargo, ya sea por una mala decisión militar del gobernador o una bien pensada estrategia indígena, esa madrugada los indígenas liderados por los toquis Pelantaro y Anganamón atacaron el campamento, matando a Óñez de Loyola, a la mayoría de los soldados españoles y a los indígenas yanaconas que los acompañaban. Así, la noticia se supo en Angol gracias a un yanacona que fue "ligero", pues "aquel que lleva nuevas malas / El tiempo suele darle prestas alas" (Arias de Saavedra \& Álvarez de Toledo, 1862, p. 25).

¿Cómo se comunicó este fracaso? ¿Por qué se conserva este mapa en el archivo del Consejo de Indias? En un contexto donde Chile, una de las colonias más lejanas del Imperio Español, no tuvo una oficina de correo (¡ni imprenta!) hasta finales del periodo colonial, las preguntas sobre la comunicación y sus agentes tienen una gran proyección historiográfica. Por ello, vale preguntarse: ¿cómo circuló la noticia? ¿Quiénes fueron los agentes comunicacionales? ¿Quién fue el responsable de las informaciones con la corte española?

Los estudios sobre la comunicación de la modernidad temprana han destacado la importancia del impreso (Darnton, 1979, 2007; Eisenstein, 1983; Febvre \& Martin, 1962) y los correos (Behringer, 2006) como los medios de cambio en las dinámicas informativas. Estas perspectivas han dejado de lado los espacios extraeuropeos, aunque actualmente se estén rescatando historiográficamente (Araneda, 2020; González, 2017; Moreno Cabanillas, 2019; Pieper, 2016; Rueda, 2012). Así, los estudios sobre el Chile colonial y su conexión comunicacional ultramarina no han sido tratados profundamente por los estudios históricos. 
En ese sentido, la noticia ${ }^{4}$ sobre Curalaba impactó no solo a la sociedad hispano-chilena, sino también a las diferentes personalidades en Lima y Madrid. Al no existir un sistema de comunicaciones garantizado por la monarquía ${ }^{5}$, el argumento de este artículo no busca analizar una "institucionalidad comunicativa", sino la heterogeneidad de agentes que permitieron la circulación de esa noticia y sus representaciones, como lo fue el mapa, por las distintas instancias políticas de la monarquía católica. Esto implica el análisis de la circulación de información desde Chile a la corte virreinal en Perú, a media distancia; y, paralelamente, con Madrid, atravesando el océano atlántico.

Los diversos agentes intentaron informar a nivel imperial un proceso de sublevación en movimiento que, a pesar de la distancia, fue rico en cartas y representaciones textuales de todo tipo para garantizar el socorro militar y económico. Aquí aparecen indígenas, soldados, secretarios y procuradores que hicieron circular las cartas con la noticia y presentaron el caso chileno en la Corte y el Consejo; en una de esas instancias, incluso, con el mapa (Figura 1) sobre la mesa. Sin embargo, como se observa, a pesar de la capacidad de gestionar el viaje de un determinado agente como representante para comunicar el suceso, los procuradores enviados no determinaron la reacción política de la metrópolis. Aquí el actor fundamental fue el Virrey quien, desde su posición política, se reforzó al constituirse en el principal informante del proceso ante el caos en el territorio chileno.

\section{LAS FORMAS DE COMUNICACIÓN EN EL CHILE DEL SIGLO XVI}

Para entender cómo se construyeron las oportunidades de comunicación epistolar tras la muerte del gobernador Óñez de Loyola, es necesario analizar las prácticas comunicacionales de este territorio hacia 1598. Desde este momento inicial se podrá evaluar las estrategias utilizadas para comunicar el desarrollo de los eventos de la gran sublevación rechemapuche. En un principio, la monarquía buscó instalar un monopolio

4 "We call political information whatever may be thought or said about events connected with the government of states and with cities and their people. The fresher it was, the more it deserved to be called 'news'”(Dooley \& Baron, 2005, p. 1).

5 Como sí sucede para el periodo posterior a 1764 (Araneda, 2020; Moreno Cabanillas, 2017). 
postal, a través de una persona particular, un oficio de Correo Mayor, proceso que también se estaba dando en Europa. Sin embargo, el envío de cartas y relaciones ${ }^{6}$ fue paralelo al envío de procuradores como representantes de las ciudades (Cunill \& Quijano, 2020; Gaudin, 2017). Esto provoca, en términos metodológicos, que el seguimiento de las cartas sea muy confuso, pudiendo aparecer en manos de distintos actores, sin ni siquiera pasar por el Correo Mayor de Indias.

Diego de Carvajal y Dávila, Correo Mayor de Indias, llegó a Lima en 1560 para poder instalar el servicio postal virreinal con la metrópolis española. Quince años antes, desde la ciudad de La Serena, el conquistador de Chile, Pedro de Valdivia, escribía una de sus más célebres cartas sobre Chile al emperador Carlos V. En ella expresaba las bondades del territorio para tener apoyo en su conquista y colonización, lo que tendrá una larga fortuna textual ${ }^{7}$. Pocos años antes se había instalado el cabildo de Santiago de Nueva Extremadura (1541) y los españoles organizaron una estrategia de conquista basada en la construcción de ciudades y el avance militar. Ninguno estaba pensando en crear una institución postal en el espacio local, no obstante, la necesidad de enviar cartas y, especialmente, informar de los méritos y las nuevas hazañas de la conquista de Chile ante el Rey.

A partir de esta carta, fechada en 4 de septiembre de 1545, es posible observar que las noticias se comunicaban, en este contexto temprano, a través de "portadores de cartas" o emisarios enviados en un momento específico. Valdivia, en su propia carta, señala:

\begin{abstract}
El portador desta carta se llama Antonio de Ulloa: es tenido por mí, y estimado por los que le conocen por sus obras y buenas maneras, por caballero e hijodalgo, y como tal se mostró en estas partes en su Real servicio, gastando para venirle a servir en ellas la hacienda que él por acá ha ganado y podido haber ${ }^{8}$ (De Valdivia, 1960).
\end{abstract}

Pedro de Valdivia confió, en ese sentido, el despacho de su carta para el Rey a Antonio de Ulloa, quien había sido parte de sus huestes y miembro del cabildo en 1542 y 1544 (Medina, 1905, p. 879). Un hombre de "buenas maneras", un "caballero e hijodalgo" componían buenas credenciales 
para elegirlo un emisario idóneo, para la entrega de la carta en la corte española. Sin embargo, como ha señalado Xabier Lamikiz para el caso de los comerciantes del siglo XviıI, la confianza es una cuestión de persuasión y percepción (Lamikiz, 2007, p. 128). No existe como concepto absoluto y, por ello, es histórico. Tanto así que la carta no llegó a manos de Carlos v. Por lo menos, no la primera copia, como se señala en una carta cinco años más tarde:
Antonio de Ulloa, el mensajero que enviaba a S. M., había abierto los despachos, y después de leídos y hecho burla dellos con otros mancebos como él, los rompió y se fue a Quito a servir a Gonzalo Pizarro ${ }^{9}$ (De Valdivia, 1960).

La ruptura de la confianza, en ese sentido, es algo material ${ }^{10}$ : la abertura de la carta y su lectura. Con ello, el efecto se destruye y la carta termina, por el momento, su trayectoria hacia España. Sin embargo, el mismo Valdivia escribe que envió a otro mensajero, sin nombre, con el duplicado de aquella carta. Esta llegó al Consejo, encontrándose actualmente en el Archivo General de Indias (AGI, patronato, 192, N. 1 R. 42).

Este particular análisis de la famosa carta, desde su dimensión comunicativa, ilustra las complejidades que existieron en su envío al Rey. Esto, especialmente, en el contexto inicial de la conquista de Chile y, más aún, por su particular localización: una de las colonias más lejanas del imperio, rodeada de grandes montañas (los Andes), un océano (el Pacífico), ríos y bosques. Esta problemática no era exclusiva de Chile, sino que desde el mismo Consejo de Indias se buscó dar un procedimiento claro.

Desde el inicio de la guerra e instalación de los españoles en el Nuevo Mundo hubo una reflexión sobre cómo gestionar las comunicaciones, especialmente porque el Rey nunca visitó esos territorios. Tal como señala Arndt Brendecke, sobre todo después de la reforma del Consejo de Indias a manos de Juan de Ovando en la década de 1560, tener "entera noticia" se había instalado como práctica de gobierno a partir de un "triángulo vigilante", donde diversos agentes

9 La Serena, 15 de octubre de 1550. Sobre la rebelión de Gonzalo Pizarro, véase el trabajo de Manfredi Merluzzi (2017).

10 Se prefiere enfatizar en la noción "material" desde los materiales mismo (en este caso, el papel, el sello y la tinta). Desde la antropología, esta reflexión ha sido realizada por Tim Ingold (2007). 
(virreyes, gobernadores, oidores, obispo, vecinos, religiosos, soldados, etcétera) tuvieron la oportunidad de observar un mismo fenómeno y el deber de informar, generando una "atención incesante con respecto a las acciones y omisiones de otros"(Brendecke, 2012, p. 256). Esta participación colectiva del gobierno a distancia (Gaudin et al., 2017) ayudaría a la gestión de las consultas tramitadas por el Consejo de Indias. Sin embargo, en ese triángulo — rey, autoridad política y observadorhay una variable que debe ser visibilizada: ¿cómo una persona podía enviar una información, incluso fuera de los ojos del virrey o del gobernador?. ¿cómo se mantuvo el secreto de una carta enviada a miles de kilómetros de distancia, sin una institución que velase por ella? Ya vimos lo que le sucedió al mismo Pedro de Valdivia.

Las leyes de indias tempranamente (1509) protegieron el envío de cartas y relaciones como una forma de control: "Qué no se impida el venir o enviar dar cuenta al Rey de los que convengan a Su Real servicio"11, dice la Ley Iv del título Xvi del libro III de Recopilación de Leyes de Indias. En ella se prohíbe que "nuestras justicias reales o personas de cualquier grado que sean" pongan impedimentos para la libre circulación de cartas hacia el Consejo de Indias. Sin embargo, la posibilidad de enviar una carta no estaba limitada a un criterio jurídico, sino al intermediario que permitiera una circulación de correspondencia en el Atlántico.

Así, paralelamente, en 1514, el rey Fernando, el católico, y su hija la Reina Juana crearon el cargo del "Correo Mayor de Indias", entregando el privilegio al jurista Lorenzo Galíndez de Carvajal, estrecho colaborador del rey. En la cédula de la concesión se ve reflejado el interés por intentar gestionar los papeles atlánticos, "y van y vienen muchas cartas y despachos ansi de las dichas Indias y tierra firme para mí y para el rey"12 (Alcázar, 1920), en un momento muy inicial del proceso de conquista del Nuevo Mundo. El objetivo era que este jurista, a la sazón de lo realizado con Europa con la concesión a la familia Tassis (Behringer, 2006, p. 341), pudiera establecer un servicio postal regular, para unir los territorios americanos con el centro de la monarquía. Sin embargo, Lorenzo y sus sucesores se enfrentaron a un proyecto gigante en un momento de continua expansión que llevó a pasar de unas pequeñas islas en 1514 a un continente completo en 1541.

11 Recopilación de Leyes de Indias, Libro III, Titulo xvi, Ley IV (años 1509, 1521 y 1603). 12 Nombramiento del Dr. Lorenzo Galíndez de Carvajal para el cargo del Correo Mayor de Indias, 14 de mayo de 1514 y 27 de octubre de 1525. 
Desde un inicio el oficio del Correo Mayor se fragmentó. Ante la incapacidad de organizar las rutas desde la metrópolis, el nieto de Lorenzo Galíndez de Carvajal, Diego, viajó en 1560 a Lima para poder instalar un sistema postal en el virreinato. Sin embargo, su privilegio fue constantemente disputado por los virreyes, quienes querían controlar las comunicaciones e informaciones que viajaban hacia Europa ${ }^{13}$. Tras una serie de disputas, fue su hijo, Diego de Carvajal y Sotomayor, quien llegó a un acuerdo con el virrey Luis de Velasco, en 1599, en el que se estableció el primer reglamento de correos peruano. En ese momento, el correo mayor renunció, en la práctica, al oficio en Nueva España ${ }^{14}$ y se hizo operativo en Perú, a partir de una serie de reglas de despacho, como los portes, su monopolio terrestre y el establecimiento de rutas hacia Quito, Lima, Cuzco y Potosí, pero nunca Santiago de Chile ${ }^{15}$.

No obstante, la conservación del privilegio de Carvajal, el virrey forzó una reducción del servicio al centro del virreinato peruano. De esta manera, a través del despacho de navíos, el virrey pudo controlar las informaciones de los territorios del Pacífico sur. Para el caso de Chile, la comunicación con el virreinato fue marítima, a través del despacho de bajeles y avisos a sus costas, lo que adquirió una mayor regularidad con el despacho del Real situado desde 1600 (Jara, 1984, p. 129).

Volvamos a una ley citada anteriormente: "Qué no se impida el venir o enviar dar cuenta al rey de los que convengan a Su Real servicio" ${ }^{\text {. }}$. Dado que el correo mayor no estableció un servicio con la gobernación de Chile hasta 1743, las autoridades y corporaciones españolas tuvieron que generar estrategias para comunicar y despachar los pliegos hacia Lima y la península ibérica. Procuradores, tanto civiles como religiosos, no solo representaron los intereses locales ante la corte, lo que ha sido llamado “carta viva” para el caso de las órdenes religiosas (Fechner \& Wilde, 2020), sino que también actuaron como portadores de cartas. Actualmente,

\footnotetext{
13 Como sucedió en 1557 con el nombramiento de Marcos Correoso, como Correo Mayor del Perú por parte del virrey Antonio de Mendoza, lo que finalmente provocó el viaje de Diego de Carvajal a territorio peruano (Montáñez, 1953, p. 45).

14 Real Decreto de Incorporación de los Correos a la Corona, 1768, Biblioteca Nacional, Sala Medina, Ms. BA 20, 7.

15 "Correo mayor- Capitulación que hizo D. Diego de Carvajal (en quien había recaído la merced de Correo Mayor de las Indias que el emperador hizo a su abuelo) con el Virrey D. Luis de Velasco, y la aceptación de este en el año de 1599, obligándose a servir el oficio y mantener la gente que fuese necesaria para ello, con tal que se le cumpliese las condiciones que pactó" (Alcázar, 1920). Lo mismo se refleja en la documentación que envíe el virrey Chinchon sobre los chasquis. Archivo General de Indias, Lima.

16 Recopilación de Leyes de Indias 1680, Libro III, Titulo XVI, Ley IV (años 1509, 1521 y 1603).
} 
la historiografía está trabajando sobre los procuradores como agentes políticos y mediadores dentro de las distintas cortes, sean europeas o extraeuropeas; sean civiles o religiosos (Álvarez-Ossorio, 1997; Cardim, 2012; Cunill \& Quijano, 2020; Gayol, 2002) ${ }^{17}$.

Estos agentes fueron mediadores entre los saberes locales y los intereses imperiales en los consejos españoles, una forma de superar la distancias en la monarquía (Gaudin, 2020). Permitieron, por un lado, tener información de primera mano sobre los acontecimientos de los territorios lejanos y, además, fueron transfer ${ }^{18}$ de distintos pliegos y cartas de personas particulares. De esta forma, la comunicación postal no solo se remite a una institución - oficio del correo mayor, en este caso- sino a diversos agentes que transitaron en los distintos espacios coloniales. Por ello, el correo colonial no se organizó de la misma forma en todas las posesiones españolas (González, 2015, p. 37). Este pluralismo comunicacional hizo, incluso, inviable plantear modelos específicos de despacho, porque fue la circunstancia y la oportunidad — como el ejemplo de Pedro de Valdivialo que hizo posible el envío de correspondencia, a pesar de que con ello no se aseguraba el éxito en el largo viaje transatlántico.

\section{Los mensajeros del desastre}

En víspera del desastre no existe una forma institucionalizada para poder despachar informaciones. Los canales eran múltiples y, por lo tanto, azarosos. El “desastre”, por tanto, circuló inorgánicamente desde la llegada de un yanacona contando "el triste caso" en Angol (Arias de Saavedra \& Álvarez de Toledo, 1862, p. 25). De hecho, si observamos el mapa, se muestra cómo Angol (San Andrés de los Infantes) fue destruida en 1600. Con el infortunio de las ciudades, en su inminente destrucción, comenzó una amplia circulación de esta funesta noticia en el virreinato: la muerte del gobernador, la sublevación indígena y la "inminente pérdida" del reino. El objetivo de esta sección es seguir el movimiento de estos mensajeros para entender cómo se comunicó este "oscuro" desastre.

Desde la muerte del gobernador Valdivia en 1553, los intentos bélicos por conquistar el territorio reche-mapuche fueron incesantes a través de una guerra a "sangre y fuego". El historiador Sergio Villalobos habla de

17 El último número de Débats de la Revista Nuevo Mundo Mundos Nuevos lo demuestra con el dossier coordinado por Caroline Cunill y Francisco Quijano.

18 Aquello que permite el desplazamiento y la circulación del medio de comunicación (Elleström, 2018, p. 9 y ss). 
una frontera "de lucha" donde "reina la inestabilidad permanente" (1995, p. 35). Gobernadores como García Hurtado de Mendoza (1557-1561) o Melchor Bravo de Saravia (1568-1575) apostaron todo a la guerra de conquista, con resultados poco concluyentes (Barros Arana, 2000, p. 61). De hecho, como señala Guillaume Boccara, los españoles reflexionaron sobre el fracaso de la guerra calificando a la población indígena como gente “sin fe, sin ley, sin Rey”, de ahí la obsesión de entender el funcionamiento de las comunidades como una forma de dominación $\left(2007\right.$, p. 31 y ss) ${ }^{19}$.

Las últimas décadas del siglo Xvi fueron significativas para la relación fronteriza. En Arauco, los reche-mapuches se resistieron violentamente a la dominación y esclavitud de los españoles. Sin embargo, Martín García Óñez de Loyola, gobernador de Chile entre 1592 y 1598, fue particularmente receptivo al argumento español sobre los motivos de la rebelión: los malos tratos derivados del servicio personal ${ }^{20}$. Con su muerte, se desencadenó el mayor alzamiento indígena del periodo colonial. Así, la victoria reche-mapuche generó a mediano plazo la construcción de una frontera en el río Biobío (Villalobos, 1995) y la transformación del ejército mediante su profesionalización, permanencia y financiamiento a través del Real Situado (Jara, 1984, pp. 17-1139).

La muerte de Loyola, por tanto, generó un impulso comunicativo nunca visto en Chile. Como se señala en Purén Indómito, la información llegó a Angol a través de un indígena que sobrevivió, probablemente, para poder comunicar la victoria mapuche. "Contó el caso en Ongol públicamente" y el corregidor de Angol, el capitán Hernando Vallejos, despachó a un soldado Juan Donaire como mensajero "encargándole vaya por el aire” (Arias de Saavedra \& Álvarez de Toledo, 1862, p. 25). A pesar de ser una fuente literaria, la forma de despacho no dista de ser la que se utilizaba en la época, tal como lo hizo Valdivia: la elección y el envío de un mensajero, en este caso, en un contexto de extrema urgencia.

19 En ese sentido, el historiador Francis Goicovich ha calificado este funcionamiento como "Estado indómito" (Goicovich Videla, 2002).

20 Eso le llevó, también, a ser muy criticado, incluso por el Marqués de Cañete, virrey del Perú, en 1592: "La [elección] de Martín García de Loyola se ha recibido muy mal por todo género de gente, por ser gran mercader, muy mísero y no soldado" En "Párrafos de carta del Marqués de Cañete a Juan de Ibarra en el Consejo, pronunciándose en contra del nombramiento de Martín García Óñez de Loyola como gobernador de Chile” (Medina, 1960, p. 188). 
Tabla 1. Agentes movilizados para comunicar los eventos de 1598

\begin{tabular}{|c|c|c|c|c|}
\hline Fecha & Mensaje & Desde & A & Fuente \\
\hline $\begin{array}{c}\text { Diciembre } \\
1598\end{array}$ & Yanacona & Curalaba & Angol & Purén Indómito \\
\hline $\begin{array}{c}\text { Diciembre } \\
1598\end{array}$ & $\begin{array}{l}\text { Soldado Juan } \\
\text { Donaire }\end{array}$ & Angol & Santiago & Purén Indómito ${ }^{21}$ \\
\hline $\begin{array}{c}\text { Diciembre } \\
1598\end{array}$ & $\begin{array}{c}\text { Soldado Luis de } \\
\text { Jufré }\end{array}$ & $\begin{array}{l}\text { Santiago - } \\
\text { Valparaíso }\end{array}$ & Lima & $\begin{array}{c}\text { Purén Indómito }{ }^{22} \\
\text { Petición de Luis } \\
\text { Jufré, procurador } \\
\text { de Chile, y acuerdo } \\
\text { tomado en Lima } \\
\text { para enviar socorro } \\
\text { al reino (Medina, } \\
\text { 1960) } \\
\end{array}$ \\
\hline $\begin{array}{l}\text { Febrero de } \\
1598\end{array}$ & Aviso del Virrey & Lima & Madrid & $\begin{array}{c}\text { Carta del Virrey } \\
\text { Velasco. Lima } 20 \\
\text { de febrero } 1599 . \\
\text { Archivo General } \\
\text { de Indias (AGI), } \\
\text { Lima, } 33 \\
\end{array}$ \\
\hline $\begin{array}{l}\text { Febrero de } \\
\quad 1600\end{array}$ & $\begin{array}{c}\text { Capitán Domingo } \\
\text { de Erazo, secretario } \\
\text { del gobernador } \\
\text { Óñez de Loyola }\end{array}$ & Santiago & Madrid & $\begin{array}{c}\text { AGI, Santa Fe 99, } \\
\text { fj. } 199\end{array}$ \\
\hline
\end{tabular}

Fuente: elaboración propia.

Este agente, sea o no Donaire, llegó a Santiago posiblemente en los últimos días de diciembre (Barros Arana, 1999, p. 182). La ciudad recibió la noticia con escándalo "como cuando se siente un terremoto" (Arias de Saavedra \& Álvarez de Toledo, 1862, p. 36). Con la elección del licenciado Pedro de Vizcarra como gobernador interino, el cabildo de Santiago, además, despachó inmediatamente desde Valparaíso al soldado Luis de Jufré para llevar la información al Virrey. En el real acuerdo de Lima del día 18 de febrero de 1599 se señala que

El general Luis Jufré [...] trujo aviso de cómo los indios de guerra de las dichas provincias habían muerto a Martín García de Loyola, gobernador

21 “[El yanacona] Contó el caso en Ongol públicamente, /Mas aunque lo contó medio al desgaire, /Despacho el capitán incontinente /A un soldado llamado Juan Donaire, /Con el aviso mísero al teniente /Encargándole vaya por el aire, / Porque la diligencia convenia/ Conforme el caso grave lo pedía” (Arias de Saavedra \& Álvarez de Toledo, 1862, p. 25).

22 "Mandó que Alonso Cid con gran cuidado / Este socorro lleve, y al proviso / a Don Luis de Jofré ha despachado / Para que al visorey lleve el aviso: / En corto, en breve tiempo fue embarcado; / Del puerto se partió Valparaíso / Con viento fresco, próspero y galerno/ El mar bonanza, manso, alegre, y tierno” (Arias de Saavedra \& Álvarez de Toledo, 1862, p. 37). 
dellas y a cuarenta soldados que con él iban desde La Imperial a Angol, tomándolos por sobresalto ${ }^{23}$.

El envío de Jufré se inserta en una serie de viajes realizados por otros mensajeros anteriormente. En Lima, este mensajero se encuentra con Jerónimo de Benavides, que había ido en nombre de Óñez de Loyola en 1597, en búsqueda de socorro y un barco ${ }^{24}$; y con el capitán Domingo de Erazo $^{25}$, quien, recién llegado de Madrid, había ejercido desde 1595 como procurador del gobernador ante la corte de Felipe II, como podemos observar en el poder que le fue dado:

Yo, Martín García de Ónez y Loyola, caballero de la orden de Calatrava, gobernador, capitán general y justicia mayor en este reino y provincia de Chile, por el Rey, nuestro señor, otorgo y conozco por esta presente carta que doy e otorgo todo mi poder [...] a vos, Domingo de Erazo, persona de entera calidad, fidelidad y suficiencia, para que [...] representando mi propia persona [...] parezcáis ante el Rey (AGI, Santa Fe 99, fj. 199).

Domingo de Erazo era una persona de "calidad" que, en el mundo colonial latinoamericano, no es una palabra vacía. Dentro de la estructura socio-racial, esto significaba que era un español europeo y puro de sangre, por lo tanto, en teoría, sin un familiar converso, ni sangre indígena o negra (Martínez, 2008). La calidad de la sangre y del fenotipo en esta época estaba asociada fuertemente a los discursos del honor y, por lo tanto, a la confianza de las personas (Undurraga, 2012).

La fidelidad y confianza también estaban asociadas a un cursus honorum dentro del imperio, Erazo no solo había luchado contra los piratas protestantes, sino también había participado en la pacificación de los rechemapuches, siendo por ejemplo nombrado como visitador de protectores, corregidores y administradores de indios (1593) (AGI, Santa Fe 99, fj. 199). Posteriormente, antes del viaje, se le nombró corregidor de Valdivia, uno de los principales puertos del sur y que tuvo una intensa participación en el control de las expediciones piratas durante el siglo XVII.

23 "11.- Petición de Luis Jufré, procurador de Chile, y acuerdo tomado en Lima para enviar socorro al reino, seguido de la Memoria de la ropa que es menester para socorrer 600 soldados que sirven en la guerra de Chile a s.m." (Medina, 1961, p. 84).

24 "10.- Petición de Domingo de Erazo y acuerdo tomado en Lima para comprar un navío y enviarlo a Chile. 30 de Enero de 1599" (Medina, 1961, pp. 82-84).

25 Para un análisis desde la óptica de la "biografía global" de la figura de Domingo de Erazo véase los trabajos y el proyecto de investigación de Jaime Valenzuela Márquez (2017). 
En esa ocasión, Erazo fue a Madrid en 1595 a través de la poco frecuente ruta de Buenos Aires. Sin embargo, a la altura de Río de Janeiro, el barco fue capturado por corsarios franceses, siendo "robado y preso", pasando un año encerrado en el puerto de La Rochelle (Francia). El proceso de comunicación fue interrumpido, lo cual es normal incluso hasta hoy en día, siendo actualmente el principal desafío de las telecomunicaciones. Este fracaso, sin embargo, resulta interesante porque da cuenta de las habilidades políticas de Erazo, quien logró llegar a Madrid gracias a un salvo conducto del Conde Henry de Coligny, que se encuentra adjuntado en su relación de méritos y servicios (AGI, Santa Fe 99, fj. 200). A pesar de que fue bien acogido en la corte y se mantuvo allí casi dos años, "perdió mucha cantidad de su hacienda y los despachos y recaudos que traía y también los papeles de sus servicios" (AGI, Santa Fe 99, fj. 200v). En ese sentido, la corte tuvo noticias de las necesidades y problemas de Chile, especialmente por la falta de dinero, personal y pertrechos para la guerra.

Llegado ya en febrero de 1599 a Lima, capital virreinal, Erazo se encontró con estos dos mensajeros: Jerónimo de Benavides, en Lima desde 1597, y Luis de Jufré, recién llegado con las noticias del gran alzamiento. Estos tres agentes, sin embargo, representan cosas distintas. Mientras Benavides y Jufré fueron elegidos para ir donde el Virrey bajo el ritmo de la urgencia, Erazo fue un representante ante la corte. No solo es un tema de distancia, sino también de significación política, Erazo era también el secretario del gobernador y debió tener experiencia para desenvolverse en la política de la corte española. Por tanto, el perfil era completamente distinto, a pesar de su experiencia como soldado en la Armada de la Mar del Sur y en la guerra de Arauco. Estos tres sujetos con tres temporalidades (1595, 1597 y 1598) no sabían realmente qué hacer, pues precisamente todos los documentos que gestionaron Erazo y Benavides obedecían a otro contexto e, incluso, las cartas que portaban tenían como remitente a una persona que ya no vivía. En esa encrucijada, había que comunicar a la corte en España.

\section{PROCURADORES... Y EL VIRREY}

En 1600, con la inminente destrucción de Angol y La Imperial, sede del obispado, Domingo de Erazo viajó como procurador del reino de Chile, para iluminar el infortunio, mientras los acontecimientos del alzamiento 
ocurrían vertiginosamente. Todavía no existía una representación completa de la sublevación, la cual llegó con la representación del mapa en 1610. El virrey se encargó de comunicar la noticia en la Corte con su carta del día 20 de febrero de 1599:

Habiendo escrito a Vuestra Majestad por vía de Tierra Firme en 22 de enero pasado, sobre el estado de las cosas de este reino, tuve cartas del [reino] de Chile a 13 de este [mes], en que me avisan que yendo el gobernador Martín García de Loyola con 35 soldados a la ligera de la ciudad Imperial a la de Angol a 23 de diciembre, por la mañana vinieron sobre él, de repente, como trescientos indios a caballo; y no dándole espacio para poderlo tomar él ni los suyos ni tenerlos aderezados, los invistieron con tanto ímpetu y furia que no pudiéndolos resistir, le mataron peleando ${ }^{26}$ (AGI, Lima 33, n. $36, \mathrm{fj} .18$ ).

De esta manera, la muerte de Loyola acontecida en diciembre de 1598 era conocida en Madrid en septiembre de 1599 (Cabrera de Córdoba, 1857). Sin embargo, la revuelta no se había acabado. Como podemos observar en el mapa, los mapuches siguieron avanzando hacia el río Biobío (de sur a norte) amenazando y destruyendo siete ciudades españolas: Santa Cruz de Coya, Valdivia, San Andrés de Los Infantes, La Imperial, Villarrica, Osorno y Arauco, entre 1599 y 1604. A pesar del complejo devenir de los acontecimientos, el mapa de 1610 representa estas ciudades como iguales. Podemos ver cómo las figuras de Santiago y Concepción, hacia 1610, se representan con un "orbe cristiano", siendo las sedes obispales. Pero el diseño arquitectónico, semejante a una iglesia, es igual para todas. Existe una amplificación de la dimensión del desastre tras 1598: no era lo mismo Santiago, una pequeña ciudad-cabeza de gobernación, que Arauco o Angol, pequeños asentamientos vinculados a un fuerte militar. En ese sentido, la misma retórica de la destrucción de las ciudades representa una imagen construida de la realidad, especialmente dada la precariedad de las ciudades al sur del Biobío.

El cabildo de las ciudades de Santiago, Concepción, Angol y La Serena enviaron a Domingo de Erazo para que volviera a España a pedir auxilio. Erazo fue elegido por su ingenio y experiencia, como señala el documento de representación, escrito por el Cabildo de Santiago: 
“es que pocos meses ya tuvo en su mano dicha negociación, y ser el ingenio, habilidad y suficiencia que, para que tan gran negocio [...] se puede confiar unánime” (AGI, Santa Fe 99, fj. 202v-203v). También había negociado el año anterior en el Consejo de Indias, por lo que conocía muy bien los mecanismos de la corte ${ }^{27}$. Por ello, ante la urgencia del contexto político chileno, se alzó como una figura ideal para llevar documentos, informar el infortunio y negociar el socorro ante el desastre. Desastre que, además, tenía una particular forma de comunicación entre los mismos indígenas para revelarse: el envío de mensajeros con cabezas de españoles muertos (AGI, Santa Fe 99, fj. 204v). Esto muestra el horror que pudo haber generado esta rebelión. Desde Madrid, además, Erazo mostró el drama chileno, lo que repercutió en la creación de un ejército permanente en la frontera y el envío de un real situado (dinero) desde las cajas fiscales limeñas para mantenerlo. Paralelamente, como se observa en su relación de méritos, siguió recibiendo informaciones de las ciudades, probablemente enviadas por intermedio del virrey y el sistema de flotas. En su negociación, los incesantes cambios de la guerra añadieron mayor urgencia al proceso, especialmente porque recibía noticias con casi seis meses de desfase (lo que tardaban las flotas) (AGI, Santa Fe 99, fj. 227v).

A pesar de la importancia de Domingo de Erazo como representante en la corte, el virrey fue la única autoridad capaz de surtir informaciones. La llegada de un viejo Francisco de Quiñones, cuñado del arzobispo de Lima Toribio de Mogrovejo, como gobernador temporal, permitió al virrey monopolizar inicialmente los contactos con Chile. De hecho, a través de los avisos de las flotas y galeones, el virrey fue enviando diversas cartas con el anexo de las cartas recibidas desde Chile. Incluso, con la anteriormente citada carta de febrero de 1599, adjuntó la del fraile Bartolomé Pérez Merino escrita en su cautiverio en Lumaco a 25 de diciembre de 1598. En ella, relata su experiencia y la cruda escena del desastre, describiendo, incluso, cómo los indígenas bailaban con la cabeza del gobernador Loyola (AGI, Lima 33, n. ${ }^{\circ}$ 36, fj. 20).

Los pliegos del virrey, en general, eran enviados como avisos por la Armada del Mar del Sur a Panamá o, particularmente para el caso de los duplicados del Virrey Velasco, a Acapulco. Una vez en el Caribe (ya sea Portobelo o Veracruz), se embarcaban hacia Sevilla y la Corte en

27 Entre las distintas experiencias, podemos destacar la llegada a Madrid, la relación con los secretarios del Perú dentro del Consejo, las discusiones internas, etcétera. Para una observación general del Consejo, véase (Schäfer, 2003). 
Madrid. Estos documentos eran enviados una vez al año (mayo-junio), aunque extraordinariamente también se enviaban avisos con barcos de la flota o particulares ${ }^{28}$. Sin embargo, la velocidad de la información sobre lo ocurrido no fue, simplemente, por la noticia en sí misma. Con ella, en el mismo pliego, venían muchas otras noticias. La velocidad de las comunicaciones, que permitió además que la corte conociera lo sucedido a mediados de 1599, estuvo marcada por las incursiones piratas de holandeses e ingleses durante esa época.

Como señala Elizabeth Montañez-Sanabria, los piratas abrieron el Pacífico, el "lago español”, a otras naciones. Eso generó, por cierto, una circulación, interacción y solapamiento de representaciones, conocimientos e informaciones sobre los ataques al Pacífico sur. Así se fueron construyendo informaciones, oficiales y extraoficiales, que serían un componente fundamental para la toma de decisiones políticas (2014, pp. 43-63). Ya desde abril de 1597, la Casa de Contratación de Sevilla había avisado al Virrey Velasco de una posible incursión inglesa por el estrecho de Magallanes (AGI, Lima 33, fj. 25). De hecho, en una carta de 3 de noviembre de 1599, el virrey envió una misiva sobre la detención de la Armada del Mar del Sur en Panamá debido a los posibles corsarios (AGI, Lima 33, n. ${ }^{\circ}$ 36, fj. 1). Eso significa no solo la detención del envío de remesas, sino también de las comunicaciones. Por ello, el virrey optó por enviar esa carta vía Nueva España.

En vísperas del Desastre de Curalaba, los mecanismos comunicacionales del virreinato estaban atentos por los corsarios. De hecho, los segundos pliegos enviados a finales de 1599 estuvieron relacionados con la información que había dado el gobernador de Chile sobre los "supuestos" ingleses en la Isla de Santa María, cerca de la frontera del Biobío (AGI, Lima 33, n. 36, fj. 52). Paralelamente, adjuntándolo en la misma carta, el virrey envió algunos avisos sobre la incursión de naves holandesas a través del duque de Medina-Sidonia, paralelamente a las noticias de la frontera en Chile:

Al 22 de junio de 1599 recibió el virrey un despacho de la Nueva España por vía de Guatemala con aviso que tuvo del duque de Medina Sidonia, de que había salido de Holanda a 8 de agosto de 98 , del puerto de

28 "Que los Virreyes gasten de la hazienda Real lo necessario para despachar avisos forçosos, con intervencion de la Iunta de Hazienda" (Felipe II, 19 de mayo de 1594). Recopilación de Leyes de Indias, Libro IV, Título xxxvir, Ley Iv. 
Rotterdam, Olivier de Noort, vecino y tabernero de la misma villa con seis navíos para pasar el estrecho de Magallanes y venir a la provincia de Chile (aGi, Lima 33, n. 36 , fj. 65).

En ese sentido, el aviso de Chile confirmó todos los temores. El gobernador Quiñones no solo debía enfrentar la sublevación indígena, la destrucción de las ciudades y la cautividad de españoles, sino también dos incursiones holandesas en 1600. La primera liderada por Oliver de Noort, y la segunda por Jacobo Mahu y los hermanos Simón y Baltasar de Cordes, que incluso llegaron a tomar el puerto de Castro (Chiloé) en abril de 1600. Esto trajo enormes complejidades en el mar para la gobernabilidad de Chile, principalmente por las formas de comunicación con el virreinato y la corte: exclusivamente marítimas. No había servicio de chasquis correos indígenas - ni tampoco un correo mayor, lo que generó un problema a la hora de informar, especialmente a partir del envío de las naves de aviso ${ }^{29}$.

Sin embargo, a pesar de la importancia de las incursiones holandesas en las comunicaciones imperiales del desastre, esto no se representó en el mapa de 1610, por ejemplo, la caída de Castro (1599) en manos piratas coincide con la destrucción de Valdivia. Sin embargo, la primera se encuentra intacta: su rápida recuperación (o abandono por parte de los piratas) fue desligada al fenómeno de la sublevación. Esto nos ayuda a ver también lo que busca representar el mapa: un desastre que involucra territorialmente a la gobernación, que requiere una solución y financiamiento local. Involucrar dentro de la negociación el problema de la piratería podría significar el fortalecimiento del centro virreinal, donde se dirigían estos navegantes en busca del tesoro del Perú.

Las informaciones de la sublevación reche-mapuche y de la incursión holandesa, por tanto, se van despachando de forma cuidadosa a través de diferentes navíos de aviso, que van transitando entre Concepción, Lima y Madrid llevando pliegos y pertrechos militares. Fue en la capital del virreinato donde se gestionaron las informaciones que fueron remitidas a la corte. Allí se encontraba negociando para Chile, Domingo de Erazo. La urgencia de estas cartas, por tanto, no van determinadas por el fulgor de la guerra en Arauco, sino más bien dentro de las dinámicas marítimas del

\footnotetext{
29 "34. Carta al cabildo de lima escrita por don Francisco de Quiñones, confirmando la presencia de un navío corsario y precauciones tomadas (6 de noviembre de 1599)" (Medina, 1961, p. 151).
} 
virrey, no obstante, este no enviase un procurador para resolver el problema geopolítico de los territorios australes.

Domingo de Erazo fue el primero en partir, pero no fue el único. En 1607, representando los intereses del gobernador y del cabildo de Santiago, viajaron a la corte madrileña el capitán Alonso González de Nájera, quien escribió Desengaño y Reparo de la Guerra del Reino de Chile (1614) y fray Juan de Lagunillas (AGI, Chile 8). Nájera tenía contactos con Alonso de Sotomayor, ex gobernador de Chile y miembro del Consejo de Indias, que era presidido por el Conde de Lemos, a quien dedicó el Desengaño. Precisamente, un "desengaño" para iluminar la guerra después del "desastre".

Sin embargo, interesante para nuestro argumento, fue el viaje del jesuita Luis de Valdivia y el capitán Lorenzo del Salto en 1609 (AGI, Patronato, 229), pues dentro de los documentos de esta negociación, se encontró el mapa presentado anteriormente. Llegando a Madrid en 1610, Valdivia tuvo mayor facilidad de entrar en los espacios del poder que el capitán Del Salto, precisamente porque el jesuita fue promocionado por el virrey del Perú con el proyecto de guerra defensiva ${ }^{30}$. Podemos ver diferentes cartas y memorias de Luis de Valdivia, donde incluso es invitado a hablar en el Consejo, al margen, una mano anónima, señala: "conviene despachar este padre Valdivia, que es muy platico de todo lo que toca a Chile" (aGi, Patronato 229, R. 8, fj. 1). Esto, en desmedro de los intentos del capitán Del Salto, quien señala en su memorial: “[Lorenzo del Salto] dice que a mucho tiempo que está en esta Corte y no ha habido lugar de besar a vuestra excelencia [Conde de Lemos] los pies" (AGI, Patronato, 229, R.8, fj. 4).

En ese sentido, bajo las negociaciones de la guerra defensiva que buscaba la pacificación de los indígenas por medio de la evangelización, el mapa aparece como la representación de un fracaso derivado del desastre de Curalaba (ciudades tachadas), pero a la vez, una esperanza salvífica (Gaune, 2016) a través de unos pequeños orbes cristianos dibujados que representan las posibles misiones. El mismo mapa, entonces, muestra el fracaso de una política, la militar; pero que puede ser reversible a través de un proyecto espiritual. Es posible, entonces, conjeturar que el mapa estuvo mientras Luis de Valdivia explicaba el proyecto a la Junta de Guerra en diciembre de 1610 (AGI, Patronato, fj. 27-30). A pesar de la agencia del

30 La "guerra defensiva" ha sido ampliamente discutida, véase Díaz Blanco (2010) y Gaune (2016). 
procurador Valdivia, su actuación fue fortalecida por el Virrey, quien le había entregado todo su apoyo político al proceso, facilitándole su camino en corte gracias a los vínculos con el secretario Pedro de Ledesma.

En ese sentido, las comunicaciones durante la sublevación fueron sustentadas, material y políticamente, por el Virrey. Con cartas y agentes, la noticia del "desastre" fue rápidamente gestionadas desde el centro virreinal para darle claridad a un Consejo ciego ante el infortunio. En ese contexto, aparece el mapa del desastre, pero también de la esperanza. Una imagen de las distintas temporalidades de las relaciones entre españoles y reche-mapuches a inicios del siglo XviI.

\section{CONGLUSIÓN}

La comunicación de un fracaso y su representación en un mapa, desde la frontera meridional del virreinato peruano, ilustra no solo el problema de la distancia sino también de las diversas estrategias de comunicación que se utilizaron para enviar una carta hacia España, en un momento de "oscuridad". No deja de ser difícil seguir los distintos itinerarios vitales de estos agentes y dado que no existía una institución específica mediadora, solo a través de ellos es posible analizar la comunicación transatlántica. Estos agentes, muchos de ellos soldados, secretarios y, posteriormente, religiosos, fueron fundamentales dentro de la vida del imperio. Sin embargo, a pesar del nivel de representación e información, la autoridad virreinal, ante el Consejo de Indias, tuvo una posición fundamental en el debate.

El mapa de la destrucción de las ciudades (1610), se encuentra enredado dentro de esas redes de comunicación y poder. Desplegado en una mesa de negociación, los distintos componentes de la monarquía buscaron diagnosticar y dar una solución al problema español de la sublevación indígena, que destruyó las siete ciudades al sur del Biobío. Sin embargo, el mapa no solo refleja la temporalidad de la destrucción, marcada por las negociaciones de Domingo de Erazo en 1600, sino también el proyecto de guerra defensiva de Luis de Valdivia en 1610. De esta manera, se observa la configuración de estas estrategias comunicacionales, donde los distintos niveles, políticos coloniales y temporales, se encontraron en la discusión de un espacio noticioso y jurisdiccional en los confines del imperio. 


\section{REFERENCIAS}

Alcázar, C. (1920). Historia del correo en América. Sucesores de Rivadeneyra.

Álvarez-Ossorio, A. (1997). Pervenire alle orecchie della Maestà': el agente lombardo en la corte madrileña. Annali Di Storia Moderna e Contemporanea, 3 , 173-223.

Araneda, J. (2020). Un Gobierno de Papel. El correo y sus rutas de comunicación en tiempos de la reforma imperial en Chile (1764-1796). Biblioteca Nacional de Chile; Centro de Estudios Diego Barros Arana.

Archivo General de Indias, AgI. (s.f.). Guerra, socorro y pacificación del Reino de Chile, 1607-1622. [Archivo histórico]. Audiencia de Chile (Chile 8). Archivo General de Indias.

Archivo General de Indias, AGI. (s.f.). Carta del cabildo de Santiago a Su Majestad. Santiago, 1 de febrero de 1607. [Archivo histórico]. Audiencia de Chile (vol. 229). Archivo General de Indias.

Archivo General de Indias, AGI. (s.f.). Fondo Patronato. [Archivo histórico]. (Santa Fe 99, fj. 199). Archivo General de Indias.

Archivo General de Indias, AGI. (s.f.). Audiencia de Lima. [Archivo histórico]. (Lima 33, n. 36 , fj. 18). Archivo General de Indias.

Archivo General de Indias, Agr. (s.f.). Copia de la carta de Bartolomé Pérez Merino. Lumaco, 25 de diciembre de 1598 inclusa en la Carta del Virrey Luis de Velasco. Lima 20 de febrero de 1599”. [Archivo histórico]. Audiencia de Lima. (Lima 33, n. ${ }^{\circ}$ 36, fj. 20). Archivo General de Indias.

Archivo General de Indias, AGI. (s.f.). Carta del Virrey Velasco. Callao, 16 de septiembre de 1597. [Archivo histórico]. Audiencia de Lima. (Lima 33, n. ${ }^{\circ}$ 36, fj. 52). Archivo General de Indias.

Archivo General de Indias, AGI. (s.f.). Carta del Virrey Velasco. Callao, 16 de septiembre de 1597. [Archivo histórico]. Audiencia de Lima. (Lima 33, n. ${ }^{\circ} 36$, fj. 25). Archivo General de Indias.

Archivo General de Indias, AGI. (s.f.). Carta del Virrey Velasco. Lima, 22 de enero de 1599. [Archivo histórico]. Audiencia de Lima. (Lima 33, n. 36, fj. 1). Archivo General de Indias.

Archivo General de Indias, AGI. (s.f.). Carta del Virrey Velasco. Callao 6 de diciembre de 1599. [Archivo histórico]. Audiencia de Lima. (Lima 33, n. ${ }^{\circ} 36$, fj. 52). Archivo General de Indias.

Archivo General de Indias, AGI. (s.f.). Relación de algunos avisos que don Luis Velasco Virrey del Perú ha tenido de que se despachaban en las islas de Holanda y Zelanda navios de corsarios para pasar el estrecho de Magallanes y entraren en esta mar del sur "en "Carta del Virrey Velasco. Callao 6 de diciembre de 1599. [Archivo histórico]. Audiencia de Lima. (Lima 33, n. 36 , fj. 65). Archivo General de Indias.

Barros-Arana, D. (Ed.). (1862). Purén Indómito [Poema del capitán Fernando Álvarez de Toledo]. Franck-Verdags-Buchnanlung.

Barros-Arana, D. (1999). Historia General de Chile (Tomo III). Editorial Universitaria y Centro de investigaciones Diego Barros Arana. 
Barros-Arana, D. (2000). Historia General de Chile (Tomo II). Universitaria, Dibam, Centro de investigaciones Diego Barros Arana.

Behringer, W. (2006). Communications Revolutions: A Historiographical Concept. German History, 24(3), 333-374. https://doi.org/10.1191/0266355406gh378oa

Boccara, G. (2007). Los vencedores. Historia del pueblo mapuche en la época colonial. Universidad de Chile ; Línea editorial IIAм ; Ocho libros editores ; Universidad Católica del Norte.

Brendecke, A. (2012). Imperio e información: funciones del saber en el dominio colonial español. Iberoamericana.

Cabrera de Córdoba. (1857). Relaciones de las cosas sucedidas en la Corte de España, desde 1599 hasta 1614 [1599-1614]. Imprenta De J. Martín Alegría.

Cardim, P. (2012). The Representatives of Asian and American Cities at the Cortes of Portugal. In P. Cardim, T. Herzog, J. J. Ruiz Ibañez, \& G. Sabatini (Eds.), Polycentric Monarchie: How did early modern Spain and Portugal achieve and maintain a global hegemony? (pp. 43-53). Sussex Academic Press.

Cunill, C., \& Quijano, F. (2020). Los procuradores de las Indias en el Imperio hispánico: reflexiones en torno a procesos de mediación, negociación y representación. Nuevo Mundo Mundos Nuevos. Débats. https://doi. org/10.4000/nuevomundo.79934

Darnton, R. (1979). The business of Enlightenment. A Publishing History of the Encyclopédie 1775-1800. The Belknap Press of Harvard University Press.

Darnton, R. (2007). What is the history of books? Revisited. Modern Intellectual History, 4(3), 495-508. https://doi.org/10.1017/S1479244307001370

De paredes, J. (Coomp.) (1681). Recopilación de Leyes de los Reynos de Indias 1680. Instituto de Cultura Hispánica.

Díaz-Blanco, J. M. (2010). Razón de estado y buen gobierno. La guerra defensiva y el imperialismo español en tiempos de Felipe III. Universidad de Sevilla.

Eisenstein, E. (1983). The Printing Revolution in Early Modern Europe [1983]. Cambridge University Press.

Elleström, L. (2018). A medium-centered model of communication. Semiotica, 224, 1-25. https://doi.org/10.1515/sem-2016-0024

Febvre, L., \& Martin, H.-J. (1962). La aparición del Libro. Uteha.

Fechner, F., \& Wilde, G. (2020). "Cartas vivas" en la expansión del cristianismo ibérico. Las órdenes religiosas y la organización global de las misiones. Nuevo Mundo Mundos Nuevos. Débats. https://doi.org/10.4000/nuevomundo.79441

Gaudin, G. (2017). Un acercamiento a las figuras de agentes de negocios y procuradores de Indias en la Corte. Nuevo Mundo Mundos Nuevos. Débats. https://doi.org/10.4000/nuevomundo.71390

Gaudin, G. (2020). Movilidad y rugosidad en la comunicación política imperial: las primeras gestiones en la Corte de los miembros de la expedición de Legazpi a Filipinas (1565-1573). Nuevo Mundo Mundos Nuevos. Débats. https://doi. org/10.4000/nuevomundo.79411

Gaudin, G., Castillo Gómez, A., Gómez, M., \& Stumpf, R. (2017). Vencer la distancia: Actores y prácticas del gobierno de los imperios español y 
portugués. Nuevo Mundo Mundos Nuevos. Débats. https://doi.org/10.4000/ nuevomundo.71453

Gaune, R. (2016). Escritura y salvación. Cultura misionera jesuita en tiempos de Anganamón, siglo XVII. Ediciones Universidad Alberto Hurtado.

Gayol, V. (2002). Los «procuradores de número» de la Real Audiencia de México, 1776-1824: propuesta para una historia de la administración de justicia en el Antiguo Régimen a través de sus operarios. Chronica Nova: Revista de Historia Moderna de La Universidad de Granada, 29, 109-139.

Goicovich-Videla, F. (2002). La etapa de la conquista (1536-1598). Origen y desarrollo del "Estado Indómito". Cuadernos de Historia (Chile), 22, 53-110.

González, N. (2015). Correos y comunicación escrita en la América colonial: esquemas de distribución de la correspondencia oficial (1514-1768). Anuario de Historia de América Latina. Jahrbuch Für Geschichte Lateinamerikas, 52, 37-64. https://doi.org/10.7767/jbla-2015-0104

González, N. (2017). Comunicarse a pesar de la distancia: La instalación de los Correos Mayores y los flujos de correspondencia en el mundo hispanoamericano (1501-1640). Nuevo Mundo Mundos Nuevos, Debates. https:// doi.org/10.4000/nuevomundo.71527

Ingold, T. (2007). Materials against Materiality. Archaeological Dialogues, 14(1), 1-16. https://doi.org/10.1017/S1380203807002127

Jara, Á. (1984). Guerra y sociedad en Chile y otros temas afines. Editorial Universitaria.

Lamikiz, X. (2007). Un "cuento ruidoso": Confidencialidad, reputación y confianza en el comercio del siglo xvinI. Obradoiro de Historia Moderna, 16, 113-142.

Martínez, M. E. (2008). Genealogical Fictions. Limpieza de Sangre, Religion, and Gender in Colonial Mexico. Stanford University Press.

Medina, J. T. (1905). Diccionario biográfico colonial de Chile. Imprenta Elzeviriana.

Medina, J. T. (Ed.). (1960). Colección de documentos inéditos para la Historia de Chile. Segunda serie (Tomo IV). Fondo Histórico y Bibliográfico J. T. Medina.

Medina, J. T. (Ed.). (1961). Colección de documentos inéditos para la Historia de Chile. Segunda serie (Tomo v). Fondo Histórico y Bibliográfico J.T. Medina.

Merluzzi, M. (2017). "Alzarse con la tierra”. Rebelión, lenguaje e imaginario político en la revuelta peruana de 1543-1548. En Soulèvements, révoltes, révolutions: Dans l'empire des Habsbourg d'Espagne, xvie-xviie siècle. Casa de Velázquez. http://books.openedition.org/cvz/1880

Mignolo, W. (1991). Cartas, crónicas y relaciones del descubrimiento y la conquista. In L. Madrigal (Ed.), Historia de la literatura hispanoamericana. Vol. 1: Época colonial (pp. 57-116). Cátedra.

Montañez, E. (2014). Challenging the Pacific Spanish Empire: Pirates in the Viceroyalty of Peru, 1570-1750 (Tesis Doctoral). University of California, Davis.

Montáñez, M. (1953). El Correo en la España de los Austrias. Consejo Superior de Investigaciones Científicas.

Moreno-Cabanillas, R. (2017). Cartas para gobernar. El establecimiento de la Administración de Correos de Cartagena de Indias (1764-1769). Editorial Académica Española. 
Moreno-Cabanillas, R. (2019). A global postal service: Empire, reform and conflict in the Spanish Atlantic in the 18th century. Ciencia Nueva. Revista de Historia y Política, 3(1), 94-111. https://doi.org/10.22517/25392662.22651

Onetto, M. (2018). Desde el desastre al Edén: experiencia y comunicación política en Chile, siglos xvi y xvir. Colonial Latin American Review, 27(3), 316-335. https://doi.org/10.1080/10609164.2018.1527526

Pieper, R. (2016). News from the New World: Spain's Monopoly in the European Network of Handwritten Newsletters during the Sixteenth Century. In News networks in Early Modern Europe (pp. 495-511). Brill. https://doi. org/10.1163/9789004277199_022

Rueda, P. (2012). La cultura escrita en el mundo atlántico colonial: claves historiográficas, retos y perspectivas. Erebea. Revista de Humanidades y Ciencias Sociales, 2, 53-76.

Schäfer, E. (2003). El Consejo Real y Supremo de las Indias. Historia y organización del Consejo y de la Casa de Contratación de las Indias (Vol. 1). Junta de Castilla; León \& Marcial Ponst.

Undurraga, V. (2012). El honor de los orígenes. En Los rostros del honor. Normas culturales y estrategias de promoción social en Chile colonial, siglo XVIII (pp. 115-146). Centro de Investigaciones Diego Barros Arana.

Valenzuela, J. (2017). Los Erazo: itinerarios estratégicos en la construcción de un linaje colonial de la periferia imperial (Chile, 1592-1692). Palimpsesto, Especial, 36-69.

Villalobos, S. (1995). Vida fronteriza en la Araucanía: El mito de la Guerra de Arauco. Andrés Bello. 